\title{
Dividendos e accruals discricionários: um estudo sobre a relação entre a política de distribuição de dividendos e a qualidade dos lucros
}

\section{Dividends and discretionary accruals: a study on the relationship between the dividend distribution policy and the earnings quality}

Dividendos y devengos discrecionales: un estudio sobre la relación entre la política de distribución de dividendos y la calidad de las ganancias

\section{William Brasil Rodrigues Sobrinho}

Mestre em Ciências Contábeis pelo PPGCon/UFES

Professor do Instituto Federal de Educação, Ciência e Tecnologia do Tocantins (IFTO)

Endereço: Av. Joaquim Teotônio Segurado, Qd 202 Sul, ACSU-SE 20, Cj 01 Lote 08 - Sul

CEP: 77.020-450 - Palmas/TO - Brasil

E-mail:william@ifto.edu.br

Telefone: +55 (63) 3229-2200

\section{Herbert Simões Rodrigues}

Mestre em Ciências Contábeis pelo PPGCon/UFES

Auditor Fiscal da Secretaria da Fazenda do Estado do Espírito Santo (SEFAZ-ES)

Endereço: Avenida João Batista Parra, n॰ 600, 4. ${ }^{\circ}$ Andar, Enseada do Suá

CEP: 29.050-375 - Vitória/ES - Brasil

E-mail: herbertsimoesrodrigues@gmail.com

Telefone: +55 (27) 3347-5283

\section{Alfredo Sarlo Neto}

Doutor em Controladoria e Contabilidade pela Universidade de São Paulo (FEA/USP)

Professor Adjunto da Universidade Federal do Espírito Santo (UFES)

Endereço: Av. Fernando Ferrari, 514 - CCJE, ED VI, S1 618 - Campus Universitário

CEP: 29.075-910 - Vitória/ES - Brasil

E-mail: sarloneto@ccje.ufes.br

Telefone: +55 (27) 4009-2794

Artigo recebido em 14/02/2014. Revisado por pares em 19/06/2014. Reformulado em 15/07/2014. Recomendado para publicação em 18/07/2014 por Sandra Rolim Ensslin (Editora Científica). Publicado em 15/12/2014. 


\title{
Resumo
}

Do ponto de vista teórico as organizações que optam por distribuição de dividendos, possuem melhor qualidade do lucro, representada por meio de um menor nível gerenciamento de resultados (TONG; MIAO, 2011). Tendo em vista que essa relação foi estudada em mercados mais desenvolvidos, o objetivo deste trabalho foi testar essa teoria em empresas listadas na BM\&FBovespa. Os resultados não confirmam a relação entre a opção das empresas em pagar dividendos e um menor nível de gerenciamento de resultados. Essa relação controversa é persistente mesmo quando se examinam empresas que pagam dividendos com maior frequência. Quando examinados os níveis de pagamento de dividendos, observou-se que as empresas da amostra, com maiores níveis de payout, inesperadamente estão associadas com maiores níveis de gerenciamento de resultados.

Palavras-chave: Dividendos. Qualidade dos lucros. Accruals discricionários.

\begin{abstract}
From a theoretical point of view organizations that choose to distribute dividends, have better earnings quality, represented by a lower level of earnings management (TONG; MIAO, 2011). Given that this relationship was studied in more developed markets, the aim of this study was to test this theory in companies listed on the BM \& FBovespa. The results do not confirm the relationship between the choice of companies to pay dividends and a lower level of earnings management. This controversial relationship is persistent even when examining companies that pay dividends more frequently. When examined the dividend payment levels, we found that the companies in the sample, with higher levels of payout, unexpectedly are associated with higher earnings management levels.
\end{abstract}

Keywords: Dividends. Earnings quality. Discretionary accruals.

\section{Resumen}

Desde un punto de vista teórico las organizaciones que optan por distribuir dividendos, tienen mejor calidad de ganancias, representada por medio de un menor nivel de gestión de los ingresos (TONG; MIAO, 2011). Teniendo en cuenta que esta relación se ha estudiado en mercados más desarrollados, el objetivo de este estudio fue probar esta teoría en empresas listadas en el BM \& F Bovespa. Los resultados no confirman la relación entre la elección de las empresas para pagar dividendos y un menor nivel de gestión de resultados. Esta relación controversial es persistente, incluso cuando se examinan las empresas que pagan dividendos con más frecuencia. Cuando se examinaron los niveles de pago de dividendos, se encontró que las empresas de la muestra, con mayores niveles de payout, de forma inesperada se asocian con mayores niveles de gestión de las ganancias.

Palabras clave: Dividendos. Calidad de las ganancias. Devengos discrecionales. 


\section{Introdução}

A ideia do conteúdo informacional dos dividendos teve origem no trabalho seminal de Miller e Modigliani (1961), o qual pressupõe que as mudanças na política de dividendos possuem conteúdo informacional sobre os lucros futuros das empresas.

O valor dos dividendos a serem distribuídos aos proprietários é decidido pelos conselhos de administração e o seu anúncio especifica quais acionistas, a partir de uma determinada data, serão contemplados (BREALEY; MYERS; ALLEN, 2008). Portanto, por não ser matéria simples, mas estratégica para as organizações, a administração da política de distribuição de dividendos é tema de diversas pesquisas que relacionam à informatividade dos lucros atuais e futuros às mudanças na sua qualidade e nos preços das ações (GRULLON; MICHAELY; SWAMINATHAN, 2002; GRULLON et al., 2005; HEALY; PALEPU, 1988).

Alguns estudos internacionais abordaram a política de dividendos tentando explicar se o simples posicionamento das empresas acerca da remuneração dos acionistas por dividendos ou ganhos de capital estaria associado à qualidade dos componentes dos lucros (HANLON; MYERS; SHEVLIN, 2007; SKINNER; SOLTES, 2009). Ressalta-se que tais pesquisas analisaram mercados mais evoluídos e com características de propriedades mais difusas, como por exemplo, o mercado estadunidense.

Neste trabalho, examinar-se-á, se o posicionamento das organizações no Brasil em distribuir ou não dividendo em determinado período, fornece elementos que possam indicar uma melhor qualidade dos lucros reportados. Tal qualidade pode ser mensurada por meio do estudo de um de seus principais componentes, os accruals, os quais podem ser divididos em discricionários e não discricionários. Parte-se, portanto, do pressuposto de que empresas que realizam pagamentos de dividendos têm maior qualidade dos lucros reportados e, portanto, menor gerenciamento dos accruals discricionários.

A justificativa deste trabalho se sustenta por fornecer resultados empíricos sobre o tema no contexto do mercado de capitais brasileiro. Apesar de existirem pesquisas que analisaram a qualidade dos lucros de empresas pagadoras de dividendos em mercados mais evoluídos (por exemplo, DANIEL; DENIS; NAVEEN, 2008; TONG; MIAO, 2011), no mercado acionário brasileiro, esse tema de pesquisa ainda é incipiente. Ademais, este estudo poderá ser útil para alguns players de mercado tais como, formuladores de estratégias organizacionais, analistas de mercado e investidores institucionais.

Espera-se que a opção por pagar dividendos seja uma referência para melhorar a qualidade dos lucros contábeis reportados, baseados em dois aspectos: (i) o pagamento de dividendos eleva a possibilidade das empresas de se endividarem. Por consequência o monitoramento pelas instituições de crédito e demais provedores de mercado também têm tendência a se elevar (EASTERBROOK, 1984) e; (ii) a opção por pagamento de dividendos pode reduzir problemas de agência, uma vez que diminuem os recursos à disposição dos acionistas controladores, facilitando o monitoramento de seus atos pelo mercado (MARTINS; FAMÁ, 2012).

Face ao exposto, o presente trabalho tem como problema de pesquisa o seguinte questionamento: Qual a relação existente entre a política de dividendos e o gerenciamento de resultados das empresas de capital aberto listadas na BM\&FBovespa?

As seções seguintes serão contempladas com uma análise da literatura sobre o tema, abordando os aspectos teóricos relacionados ao gerenciamento de resultados e a política de 
dividendos, bem como o desenvolvimento da hipótese de pesquisa. Em seguida serão desenvolvidas a metodologia, a coleta e o tratamento dos dados e apresentados os modelos econométricos adotados. Após, serão discutidos os resultados empíricos e aplicados os testes de sensibilidade. Por fim, serão abordadas as possíveis justificativas e implicações dos resultados da pesquisa, bem como as suas limitações.

\section{Referencial Teórico}

\subsection{Qualidade do Lucro Contábil}

A literatura argumenta que as escolhas contábeis, baseadas em legalidade e respeito aos princípios fundamentais de contabilidade, podem ser identificadas como forma principal de mensurar a qualidade dos lucros (FIELDS; LYS; VINCENT, 2001). Entretanto, a definição da qualidade do lucro contábil é um tema controverso e muitas são as formas de abordagens e interpretações (LUSTOSA et al., 2010).

Em seu trabalho sobre uma revisão das proxies sobre a qualidade do lucro Dechow, Ge e Schrand (2010) ressaltam três características importantes: (i) a relevância da informação num contexto de decisão; (ii) a informatividade sobre o desempenho financeiro da empresa após a tomada de decisão e (iii) a capacidade do sistema contábil em mensurar performances. Os mesmos autores ainda classificaram as proxies para a qualidade do lucro em três categorias: (i) as propriedades dos lucros; (iii) as resposta dos investidores ao lucro e (iii) os indicadores externos de distorções do lucro (DECHOW; GE; SCHRAND, 2010).

Em relação às propriedades do lucro, objeto deste trabalho, pressupõe a teoria que níveis elevados de accruals acarretam lucros de baixa qualidade, pois representam uma redução da persistência de seus componentes. Neste sentido, os accruals, que são aqueles elementos relacionados às escolhas contábeis, são também os componentes que causam alterações no resultado do período sem a real participação dos fluxos de caixa em função do regime de competência das empresas (SOUZA et al., 2013).

Diversos trabalhos associam accruals discricionários ao gerenciamento de resultados ou lucros de baixa qualidade (BARTOV; GUL; TSUI, 2000; BECKER et al., 1998; HEALY, 1985; HENINGER, 2001; LO, 2008; MYERS; MYERS; OMER, 2003; WARFIELD; WILD; WILD, 1995). Contudo, Healy e Wahlen (1999) elencam quais seriam os pressupostos motivacionais do gerenciamento de resultados, classificando-os em elementos que envolvem (i) as questões relacionadas ao mercado de capitais, (ii) as questões contratuais e por fim (iii) as questões regulatórias.

Em se tratando de questões regulatórias, Rezende e Nakao (2012) pesquisaram o efeito que a tributação sobre o lucro exerce no gerenciamento de resultado das empresas brasileiras, encontrando uma relação significativamente negativa. Segundo os autores, isso revela o efeito que a vinculação das práticas contábeis às normas tributárias exerce sobre o conteúdo informacional do lucro. Formigoni, Antunes e Paulo (2009), também destacaram que os aspectos tributários, têm peso significativo dentre os vários incentivos para gerenciamento de resultados no Brasil.

Martinez (2008) menciona as tipologias do gerenciamento de resultado e suas motivações específicas: (i) income maximization/minimization, finalidade de melhorar ou piorar o resultado contábil; (ii) income smoothing que consiste na suavização de resultados 
por meio de práticas contábeis que visam reduzir a variância do lucro contábil e (iii) take a bath, em que os gestores manipulam os resultados reduzindo o reconhecimento dos lucros correntes para aumentá-los em exercícios futuros.

Com o objetivo de identificar os níveis de accruals discricionários, ou seja, maior ou menor qualidade do lucro contábil, este trabalho, abordará a análise das propriedades dos accruals anormais na composição da qualidade dos lucros reportados. Para a estimação dos accruals discricionários, utilizar-se-á o modelo de Jones (1991), modificado por Dechow, Sloan e Sweeney (1995).

\subsection{Políticas de Dividendos Adotadas por Empresas no Brasil}

Bastante controverso no campo das finanças corporativas, desde o estudo seminal de Miller e Modigliani (1961), o tema "dividendos" foi explorado por diversos autores, não havendo consenso sobre a sua importância e qual seria a política ideal a ser adotada pelas organizações (MARTINS; FAMÁ, 2012).

No Brasil, a política de dividendos é um tema interessante, tendo em vista o crescimento significativo da Bolsa de Valores, principalmente com o número recorde de IPO's (Initial Public Offerings) em 2007, onde o investidor passou a priorizar os ganhos de capital, bem como a implantação de boas práticas de governança corporativa (MARTINS; FAMÁ, 2012).

Pela abordagem fiscal, a legislação brasileira, a partir de 1996, definiu que a distribuição de dividendos para qualquer sócio ou acionista, passou a ser isenta do imposto de renda, diferenciando-se da maioria dos países (BRASIL, 1995). Embora a empresa tenha a alternativa de remunerar os acionistas por meio dos juros sobre capital próprio (JSCP), o qual é dedutível para fins fiscais, muitas empresas pagam dividendos (tributado em nível da empresa) apesar da vantagem tributária dos juros sobre o capital próprio (tributado em nível do acionista) (BOULTON; BRAGA-ALVES; SHASTRI, 2012).

Nesse sentido, a legislação brasileira parece invalidar, em parte, o estudo da teoria da preferência tributária dos investidores, onde seus expoentes afirmam que a retenção dos fluxos de caixa poderia favorecer o valor das ações (BRENNAN, 1970; LITZENBERGER; RAMASWAMY, 1979). De acordo com essa teoria, se os dividendos forem indesejados (pela aversão à carga tributária), quanto maior o payout praticado pelas empresas, menor seria a valorização da ação (LOSS; SARLO NETO, 2003). De fato, Abreu (2002) comparou a legislação tributária brasileira e estadunidense e concluiu que o tratamento tributário pode afetar a preferência dos investidores pelo recebimento ou não de dividendos.

Por outro lado, conforme argumentam Loss e Sarlo Neto (2003), no mercado, existem investidores que, independentemente da carga tributária, querem receber dividendos regulares. Desta forma, a política de dividendos adotada pela empresa atrairá os investidores com afinidades congruentes.

Complementarmente ao incentivo fiscal, a legislação societária brasileira contemplou o direito do investidor ao valor mínimo de dividendos, levando a uma interferência do sistema jurídico brasileiro (code law) na política de distribuição dos fluxos de caixa das empresas. De acordo com a lei, a política de distribuição dos fluxos de caixa deverá estar prevista nos estatutos sociais, caso contrário, ficam vinculadas ao patamar legal mínimo de metade do lucro contábil (BRASIL, 1976). 
Considerando o imperativo legal no Brasil, tal situação poderia tornar ineficientes mecanismos de atração de capitais no mercado acionário brasileiro, principalmente no que se refere à afinidade entre perfis (investidor/empresas), o que poderia mitigar o efeito clientela. De fato, algumas pesquisas desenvolvidas no mercado acionário brasileiro não apontaram relação do efeito clientela nas escolhas dos investidores (PEROBELLI; SANTOS, 2006; PEROBELLI; ZANINI; SANTOS, 2009; PROCIANOY; VERDI, 2003, 2009; SANTOS et al., 2004).

Entretanto, Holanda e Coelho (2012) argumentam a possibilidade desse efeito não pode ser rejeitado de forma conclusiva, pois eles confirmaram parcialmente esta relação ao utilizarem como proxy para o efeito clientela, elementos como a estrutura de propriedade, o sistema de governança corporativa e o perfil dos acionistas, o que poderiam influenciar a política de dividendos das empresas.

Em seus estudos, Fama e French (2001) identificaram que o tamanho da firma, a oportunidade de crescimento e a rentabilidade são três fatores importantes para o pagamento de dividendos. No Brasil, algumas pesquisas indicaram que o tamanho da empresa (BOULTON; BRAGA-ALVES; SHASTRI, 2012; IQUIAPAZA; LAMOUNIER; AMARAL, 2008); o lucro líquido (DECOURT; PROCIANOY, 2012) e a presença de fluxos de caixa (MOTA; EID JÚNIOR, 2007), influenciaram positivamente no pagamento de dividendos, enquanto o endividamento (IQUIAPAZA; LAMOUNIER; AMARAL, 2008) e a oportunidade de crescimento influenciaram negativamente (JUNIOR et al., 2010).

\subsection{Relação entre a Política de Dividendos e a Qualidade dos Lucros Reportados e o Desenvolvimento da Hipótese}

Muitos estudos acadêmicos examinaram se as empresas são oportunas em gerenciar resultados em momentos de eventos corporativos importantes, tais como ofertas de ações (DUCHARME; MALATESTA; SEFCIK, 2004; SHIVAKUMAR, 2000); planos de aquisições (BERGSTRESSER; DESAI; RAUH, 2006); maximização de prêmios e bônus para os administradores (HEALY, 1985); atendimento às expectativas criadas por analistas de mercado (DEGEORGE; PATEL; ZECKHAUSER, 1999) ou até mesmo, questões relacionadas às mudanças nas políticas remuneratórias das organizações (CHEN; SHEVLIN; TONG, 2007).

Daniel, Denis e Naveen (2008), utilizam uma amostra extraída do S\&P500 ao longo do período de 1992 a 2005 e descobriram que as empresas com políticas remuneratórias sob a forma de distribuição de dividendos tendem a reconhecer receitas discricionárias, pois os fluxos de caixa gerados não suportam tais políticas. Segundo os autores, esse comportamento seria esperado pelo fato do endividamento ser sustentado por contratos que trazem restrições às remunerações dos proprietários.

Em contrapartida, Tong e Miao (2011) discorrem que os anúncios de dividendos fornecem maior credibilidade aos lucros reportados pelas empresas. Neste cenário, os dividendos somente seriam pagos, caso existisse uma boa qualidade dos lucros, ou seja, um baixo nível de accruals discricionários. Comprometendo-se a realizar o pagamento de dividendos, as empresas podem convencer os investidores sobre a boa qualidade dos lucros reportados (SKINNER; SOLTES, 2009). Logo, parece ser inviável para as empresas realizarem pagamentos regulares de dividendos, se o lucro não for representado por elevados fluxos de caixa.

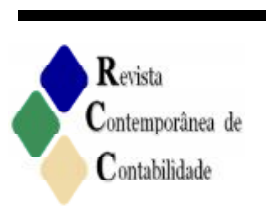


Nesse aspecto, a opção pelo pagamento de dividendos, só deve ser realizada pela empresa, caso esta possua fluxo de caixa suficiente. Portanto, as empresas pagadoras de dividendos seriam incentivadas a reportar lucros de melhor qualidade, ou seja, com menores níveis de accruals discricionários (menor gerenciamento de resultados). Partindo dessa premissa, o presente trabalho testa a seguinte hipótese pesquisa:

$H_{0}$ : Empresas que distribuem dividendos possuem lucros de melhor qualidade, ou seja, realizam menos gerenciamento de resultados.

Pela hipótese formulada, espera-se que a sinalização em pagar dividendos seja um indicativo de qualidade do lucro, por duas razões: (i) seria um ônus para a empresa distribuir dividendos sem que exista uma contrapartida de fluxos de caixa; (ii) níveis maiores de payout também induziria o investidor externo a acreditar que não existem margens suficientes para expropriações pelos acionistas gestores, o que mitiga o problema de agência (BORTOLON, 2013).

Esses argumentos sugerem que as empresas que pagam dividendos são mais propensas a relatar os ganhos que estão associados com reais realizações de fluxos de caixa esperados e que estão menos contaminados por gerenciamentos oportunistas (TONG; MIAO, 2011).

\section{Metodologia}

\subsection{Amostra: Coleta e Tratamento dos Dados}

Os dados contábeis e financeiros necessários à realização do presente trabalho foram obtidos por meio do software Economatica ${ }^{\circledR}$ e relacionam-se ao período de 2003 a 2012 . A amostra é composta por companhias abertas com ações negociadas na bolsa de valores de São Paulo (BM\&FBovespa).

\section{Tabela 1 - Tratamento dos Dados}

\begin{tabular}{lc}
\hline Modelo & Observações \\
\hline Observações iniciais -740 firmas/ano & 7.430 \\
(-) Setor finanças e fundos & $(800)$ \\
(-) Células vazias ou observações com erros & $(4.186)$ \\
= Amostra Final & 2.444 \\
Pagadoras de Dividendos & 1.491 \\
Não Pagadoras de Dividendos & 953 \\
\hline
\end{tabular}

Fonte: Dados da pesquisa.

A exclusão dos setores finanças e fundos (800 observações) decorre da inviabilidade de utilização da métrica adotada para a estimação dos accruals. Tratando-se de setores regulados pelo Banco Central do Brasil - BACEN, possuem características próprias que prejudicam uma comparação com os demais setores pertencentes à amostra.

Após a exclusão desses setores, foi realizada a operacionalização dos dados, ou seja, cálculos de todas as variáveis que farão parte dos modelos econométricos. A informação referente à variável de governança corporativa (NM2) foi obtida diretamente no site da BM\&FBovespa. Também foram excluídas as observações com erros nos cálculos, células 
vazias e ainda as observações com payout negativo, seguindo procedimento adotado por Holanda e Coelho (2012).

A amostra final consiste em 2.444 observações, das quais 1.491 são pagadoras de dividendos e 953 são não pagadoras de dividendos, o que representa respectivamente $60,97 \%$ e $39,03 \%$ da amostra final, no período de 2003 a 2012. No que tange ao tratamento dos outliers (observações extremas), optou-se por realizar a "winsorização" dos dados. Foram considerados extremos $2 \%$ dos valores das variáveis, sendo $1 \%$ no limite inferior e $99 \%$ no limite superior.

\subsection{Modelos Empregados}

Em razão do período de pesquisa abordar um espaço temporal de não obrigatoriedade da divulgação da demonstração do fluxo de caixa, a estimação dos accruals totais será realizada pelo enfoque do balanço patrimonial (DECHOW; SLOAN; SWEENEY, 1995).

$$
A C C_{b s}=\left(\Delta A C_{t}-\Delta P C_{t}-\Delta \text { Caixa }_{t}+\Delta D^{\prime} v_{t}-D E P_{t}\right) / A_{t-1}
$$

Em que: $\triangle \mathrm{AC}=$ Variação no Ativo Circulante; $\Delta \mathrm{PC}=$ Variação no Passivo Circulante; $\Delta$ Caixa $=$ Variação no Caixa e Equivalente de Caixa, $\Delta$ Dív $=$ Variação nas Dívidas de Longo Prazo Incluídas no Passivo Circulante e DEP = Depreciação.

A Estimação dos accruals discricionários será realizada pelo modelo modificado de Jones (1991) proposto por Dechow, Sloan e Sweeney (1995). A estimação da regressão será realizada com a inclusão da constante, objetivando mitigar os efeitos da heterocedasticidade e os problemas de escala, bem como, será incorporado no modelo a variável ROA para controlar a performance da firma (KOTHARI; LEONE; WASLEY, 2005):

$$
A C C_{b s}=\beta_{0}+\beta_{1}\left(1 / A T_{t-1}\right)+\beta_{2}\left(\Delta R E V_{t}-\Delta R E C_{t}\right)+\beta_{3}\left(P P E_{t}\right)+\beta_{4}\left(R O A_{t}\right)+\varepsilon
$$

Em que: $A C C_{b s}=$ Accruals totais estimados pela equação (1); $A T=$ Ativo Total; $\triangle R E V$ $=$ Variação da Receita Líquida; $\triangle R E C=$ Variação dos Recebíveis; $P P E=$ Ativo Imobilizado; $R O A=$ Lucro Líquido/Ativo Total e $\varepsilon=$ termo de erro da regressão (estimação dos accruals discricionários). Todas as variáveis foram escalonadas pelo ativo total em t-1.

Como o objetivo de avaliar se existe uma relação entre pagamento de dividendos e o gerenciamento de resultados, a regressão será estimada, conforme modelo a seguir:

$$
\begin{gathered}
A C C D=\beta_{0}+\beta_{1} D I V+\beta_{2} T A M+\beta_{3} M T B+\beta_{4} C R E S+ \\
\beta_{5} M L+\beta_{6} E N D+\beta_{7} F C O+\beta_{8} P M A+\beta_{9} P E R+\beta_{10} N M 2+\varepsilon
\end{gathered}
$$

Em que: $\mathrm{ACCD}=$ gerenciamento de resultados, tendo como proxy o valor dos accruals discricionários estimados pela equação (2); DIV = Variável dummy, 1 caso ocorra pagamento de dividendos, 0 caso contrário; $T A M=$ Logaritmo Natural do Ativo Total; MTB $=$ Valor de $\operatorname{Mercado}_{(31 / 03 / t+1)} /$ Patrimônio Líquido $_{(31 / 12 / t)} ; C R E S=\left(\operatorname{Rec}_{t}-\operatorname{Rec}_{t-1}\right) / \operatorname{Rec}_{t-1} ; M L=$ Lucro Líquido/Receita; $E N D=$ (Passivo Circulante + Passivo Não Circulante)/Ativo Total; $F C O=$ Fluxo de Caixa Operacional; $P M A=$ Participação dos 3 Maiores Acionistas, razão entre as ações ordinárias pertencentes aos maiores acionistas e o total de ações da empresa; 
$P E R=$ Variável dummy, 1 caso EBITDA $<0,0$ caso contrário e NM2 $=$ dummy, 1 quando listada no Nível 2 (N2) ou Novo Mercado (NM) e 0 caso contrário.

A variável de pagamento de dividendos (DIV) indica apenas que o pagamento foi realizado naquele exercício financeiro, restringindo a análise do gerenciamento do resultado ao período correspondente do pagamento. Em razão dessa restrição da variável (DIV), será realizada uma análise, no que tange a "persistência" dos pagamentos de dividendos das firmas (TONG; MIAO, 2011, p. 194).

$$
\begin{gathered}
A C C D=\beta_{0}+\beta_{1} P P_{-} D I V+\beta_{2} T A M+\beta_{3} M T B+\beta_{4} C R E S+ \\
\beta_{5} M L+\beta_{6} E N D+\beta_{7} F C O+\beta_{8} P M A+\beta_{9} P E R+\beta_{10} N M 2+\varepsilon
\end{gathered}
$$

Em que: $P_{-} D I V=$ Variável dummy, 1 caso ocorra o pagamento de dividendos de forma frequente durante 4 ou mais anos (t-3 a t), 0 caso contrário.

A equação 4 terá o objetivo de demonstrar que a regularidade no pagamento de dividendo, exige das empresas uma melhor qualidade dos seus lucros. Logo, essa "persistência" dos pagamentos dos dividendos deverá ser suportada por lucros com menores níveis de accruals discricionários.

Por fim, a amostra será classificada em firmas que pagam dividendos elevados $\left(B I G_{-} D I V\right)$ e em firmas que pagam menores dividendos $\left(S M A L L \_D I V\right)$. Esse procedimento tem o objetivo verificar se há relação entre o nível do pagamento (payout) de dividendo e a qualidade dos lucros das firmas.

$$
\begin{aligned}
& A C C D=\beta_{0}+\beta_{1} B I G_{-} D I V+\beta_{2} S M A L L_{-} D I V+\beta_{3} T A M+\beta_{4} M T B+ \\
& \beta_{5} C R E S+\beta_{6} M L+\beta_{7} E N D+\beta_{8} F C O+\beta_{9} P M A+\beta_{10} P E R+\beta_{11} N M 2 \varepsilon
\end{aligned}
$$

Em que: $B I G \_D I V=$ variável dummy, que assume 1 caso o payout seja superior a 0,25 , e 0 caso contrário; $S M A L L_{-} D I V$, = variável dummy, que assume 1 caso o payout seja inferior a 0,25 , e 0 caso contrário.

A equação 5 objetiva demonstrar a relação entre o nível de distribuição de dividendos e a qualidade do lucro contábil, esperando, dessa forma, que empresas com maiores níveis de pagamento de dividendos tenham lucros de melhor qualidade.

Os modelos serão controlados com a variável (TAM) tamanho da firma. Espera-se uma relação negativa desta variável com a variável dependente de forma que empresas maiores tendem a adotar práticas contábeis que reduzam a atenção política (WATTS; ZIMMERMAN, 1986, p. 251).

Para oportunidade de crescimento serão utilizadas as variáveis market-to-book (MTB) e crescimento das receitas (CRES). Espera-se que estas variáveis sejam relacionadas a maiores níveis de accruals discricionários, ou seja, empresas em crescimento são mais propensas a apresentar estimativas positivas, elevando assim o nível dos accruals anormais (MCNICHOLS, 2000).

Para a rentabilidade da empresa será utilizada a variável margem líquida (ML), bem como a variável perda (PER), que indicará se a empresa teve um EBITDA negativo. Na análise preliminar da equação (5) observou-se que a variável ROA era altamente correlacionada com a variável END, o que poderia prejudicar a análise dos resultados. Portanto optou-se por utilizar a margem líquida (ML) ao invés do retorno sobre o ativo

11 ISSN 2175-8069, UFSC, Florianópolis, v. 11, n. 24, p. 03-24, set./dez. 2014 
(ROA), para mitigar o efeito da multicolinearidade. A variável de endividamento (END) tem o objetivo de controlar o efeito no gerenciamento de resultados.

Embora o estudo de Erfurth e Bezerra (2012) não tenha apresentado resultado estatisticamente significativo de que, melhores níveis de governança corporativa acarretam em menores níveis de gerenciamento de resultados pelas empresas listadas na BM\&FBovespa, decidiu-se acrescentar a variável (NM2), para capturar o efeito da adesão aos segmentos especiais de governança corporativa pelas firmas.

Para controlar o efeito da estrutura de propriedade no gerenciamento de resultados foi incorporada ao modelo a variável PMA - participação dos três maiores acionistas. Espera-se uma relação positiva entre concentração e gerenciamento de resultados, em razão do ambiente code law (LEUZ; NANDA; WYSOCKI, 2003).

Os modelos foram estimados, por meio de regressões robustas com erros clusterizados por setor e ano, conforme proposta de Petersen (2009). A estimação com erros robustos por clusters apresenta os erros padrões que são corrigidos por heterocedasticidade, bem como, um melhor controle da dependência dos resíduos em dados cross-section e séries temporais.

\section{Análise dos Resultados}

\subsection{Estatística Descritiva}

A Tabela 2, a seguir, apresenta a estatística descritiva dos dados contidos na amostra, bem como os testes estatísticos relacionados a diferenças de médias e medianas. Optou-se por demonstrar a estatística descritiva segregada por firmas pagadoras de dividendos e não pagadoras de dividendos.

Observa-se que, em média, o tamanho (TAM), fluxo de caixa (FCO) e margem líquida (ML) das firmas pagadoras de dividendos são superiores às empresas não pagadoras de dividendos, enquanto, o endividamento (END), em média, é superior nas empresas não pagadoras de dividendos. Tais resultados preliminares são condizentes com as pesquisas anteriores, realizadas no mercado de capitais brasileiro, a respeito dos determinantes de distribuição de dividendos. No que tange aos accruals discricionários, as empresas não pagadoras de dividendos, obtiveram, em média, níveis maiores do que as empresas pagadoras de dividendos, embora com desvio padrão superior.

Com exceção da média da variável CRES (crescimento da receita) e PMA (participação dos três maiores acionistas), todas as demais variáveis apresentam significância estatística das diferenças de médias e medianas, para as duas situações, pagadoras e não pagadoras de dividendos. Em razão de sua peculiaridade, as variáveis de abordagem qualitativa (dummies) foram omitidas.

Para realizar o teste de diferença de média foi utilizado o teste $t$, enquanto para as diferenças de medianas foi o utilizado o teste não paramétrico de Wilcoxon. A vantagem do teste de Wilcoxon consiste na "não dependência do pressuposto de normalidade para as duas populações" (LEVINE et al., 2012, p. 457). 
Dividendos e accruals discricionários: um estudo sobre a relação entre a política de distribuição de dividendos...

Tabela 2 - Estatística Descritiva

\begin{tabular}{|c|c|c|c|c|c|c|c|c|}
\hline \multirow[b]{2}{*}{ Variáveis } & \multicolumn{3}{|c|}{ Pagadoras de Dividendos (a) } & \multicolumn{3}{|c|}{ Não Pagadoras de Dividendos (b) } & \multicolumn{2}{|c|}{ Diferença $(\mathbf{a}-\mathbf{b})$} \\
\hline & Média & Mediana & $\begin{array}{l}\text { Desvio } \\
\text { Padrão }\end{array}$ & Média & Mediana & $\begin{array}{l}\text { Desvio } \\
\text { Padrão }\end{array}$ & Média & Mediana \\
\hline$A C C D$ & $-0,002$ & $-0,020$ & 0,133 & $-0,015$ & $-0,033$ & 0,221 & $0,013^{*}$ & $0,012 * * *$ \\
\hline$T A M$ & 14,628 & 14,625 & 1,643 & 13,218 & 13,305 & 1,782 & $1,409 * * *$ & $1,320^{* * *}$ \\
\hline MTB & 2,503 & 1,675 & 3,094 & 1,605 & 0,838 & 3,984 & $0,898 * * *$ & $0,837^{* * *}$ \\
\hline CRES & 0,215 & 0,134 & 0,429 & 0,207 & 0,106 & 0,671 & 0,008 & $0,028^{* * *}$ \\
\hline$M L$ & 0,209 & 0,098 & 0,563 & $-0,628$ & $-0,013$ & 2,686 & $0,837 * * *$ & $0,111 * * *$ \\
\hline$E N D$ & 0,523 & 0,535 & 0,170 & 1,304 & 0,744 & 1,842 & $-0,781 * * *$ & $-0,209 * * *$ \\
\hline FCO & 0,118 & 0,125 & 0,162 & 0,026 & 0,063 & 0,264 & $0,092 * * *$ & $0,062 * * *$ \\
\hline PMA & 0,464 & 0,422 & 0,200 & 0,477 & 0,426 & 0,213 & $-0,013$ & $-0,004$ \\
\hline
\end{tabular}

Obs.: ***,**,* significante a $1 \%, 5 \%$ e $10 \%$, respectivamente, baseado no teste $-\mathrm{t}$ para diferenças de médias e no teste de Wilcoxon para diferenças de medianas. A amostra consiste em 2.444 observações, das quais 1.491 são pagadoras de dividendos e 953 são não pagadoras de dividendos, no período de 2003 a 2012. $A C C D=$ gerenciamento de resultados, tendo como proxy o valor dos accruals discricionários estimados pela equação (2);

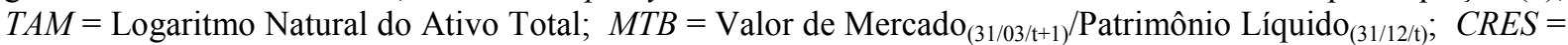
$\left(\operatorname{Rec}_{\mathrm{t}}-\mathrm{Rec}_{\mathrm{t}-1}\right) / \mathrm{Rec}_{\mathrm{t}-1} ; M L=$ Lucro Líquido/Receita; $E N D=($ Passivo Circulante + Passivo Não Circulante $) /$ Ativo Total; $F C O=$ Fluxo de Caixa Operacional e $P M A=$ Participação dos 3 Maiores Acionistas.

Fonte: Dados da pesquisa.

\subsection{Correlação entre as Variáveis}

A Tabela 3 apresenta a correlação entre os dados contidos na amostra. Para uma maior abrangência, a tabela demonstra a correlação de Pearson, na parte inferior, bem como a correlação de Spearman, na parte superior da matriz de correlação.

\section{Tabela 3 - Correlação Entre as Variáveis}

\begin{tabular}{|c|c|c|c|c|c|c|c|c|c|c|c|c|c|c|}
\hline Variáveis & $A C C D$ & $\boldsymbol{T A M}$ & $M T B$ & CRES & $M L$ & $E N D$ & $F C O$ & $P M A$ & $D I V$ & $P_{-} D I V$ & $\begin{array}{c}B I G \\
D I V\end{array}$ & $\begin{array}{c}\text { SMALL } \\
\text { DIV }\end{array}$ & PER & $N M 2$ \\
\hline$\overline{A C C D}$ & & $-0,11 * *$ & 0,03 & $0,23 * *$ & $0,11 * *$ & $-0,10 * *$ & $-0,61 * *$ & $0,06^{* *}$ & $0,08 * *$ & 0,02 & 0,01 & $0,09 * *$ & $-0,13 * *$ & $0,08 * *$ \\
\hline$T A M$ & $-0,07 * *$ & & $0,34 * *$ & $0,16^{* *}$ & $0,38 * *$ & $-0,10 * *$ & $0,17 * *$ & $0,10 * *$ & $0,36^{* *}$ & $0,29 * *$ & $0,30 * *$ & $0,07 * *$ & $-0,32 * *$ & $0,34 * *$ \\
\hline$M T B$ & 0,03 & $0,16^{* *}$ & & $0,24 * *$ & $0,37 * *$ & $-0,16^{* *}$ & $0,26^{* *}$ & $0,10 * *$ & $0,30 * *$ & $0,22 * *$ & $0,26 * *$ & $0,05^{*}$ & $-0,33 * *$ & $0,26 * *$ \\
\hline CRES & $0,23 * *$ & $0,09 * *$ & $0,10 * *$ & & 0,18 ** & $-0,11 * *$ & 0,00 & $0,05 * *$ & 0,10 ** & $-0,03$ & $-0,05 * *$ & $0,20 * *$ & $-0,24 * *$ & $0,20 * *$ \\
\hline$M L$ & $0,07 * *$ & $0,22 * *$ & $0,09 * *$ & $0,12 * *$ & & $-0,42 * *$ & $0,32 * *$ & $0,09 * *$ & $0,55^{* *}$ & $0,37 * *$ & $0,36^{* *}$ & $0,24 * *$ & $-0,48 * *$ & $0,20 * *$ \\
\hline$E N D$ & $-0,05$ & $-0,37 * *$ & $-0,12 * *$ & $-0,15^{* *}$ & $-0,50 * *$ & & $-0,09 * *$ & $-0,04$ & $-0,48^{*}$ & $-0,27 * *$ & $-0,27 * *$ & $-0,17 * *$ & $0,27 * *$ & $-0,15 * *$ \\
\hline$F C O$ & $-0,63 * *$ & $0,17 * *$ & $0,15^{* *}$ & $-0,12 * *$ & $0,21 * *$ & $-0,18 * *$ & & $-0,03$ & $0,23 *$ & $0,19 * *$ & $0,20 * *$ & 0,03 & $-0,35^{* *}$ & $-0,02$ \\
\hline PMA & $0,07 * * *$ & $0,06^{* *}$ & $0,08 * *$ & $0,06 * *$ & $0,04 *$ & $=\quad-0,03$ & $-0,02$ & & $-0,01^{*}$ & $-0,10 * *$ & $-0,01$ & 0,00 & $-0,05 * *$ & 0,03 \\
\hline$D I V$ & 0,04 & $0,38 * *$ & $0,13 * *$ & 0,01 & $0,23 * *$ & $-0,31 * *$ & 0,21 & $-0,03$ & & $0,64 * *$ & $0,70 * *$ & $0,37 * *$ & $-0,43 * *$ & $0,18 * *$ \\
\hline$P_{-} \mathrm{DIV}$ & $-0,02$ & $0,31 * *$ & $0,08 * *$ & $-0,09 * *$ & $0,16^{* *}$ & $=-0,20 * *$ & $0,18 * *$ & $-0,10 * *$ & $0,64 * *$ & & $0,55^{* *}$ & $0,10 * *$ & $-0,27 * *$ & $0,08 * *$ \\
\hline$\overline{B I} G \_D I V$ & $-0,02$ & $0,32 * *$ & $0,13 * *$ & $-0,08 * *$ & $0,14 * *$ & $-0,22 * *$ & $0,19 * *$ & $-0,02$ & $0,70 * *$ & $0,55 * *$ & & $-0,45 * *$ & $-0,29 * *$ & $0,14 * *$ \\
\hline$S M \bar{A} L L \_D I V$ & $0,08 * *$ & $0,07 * *$ & 0,00 & $0,11 * *$ & $0,11 * *$ & $-0,12 * *$ & $0,02 * *$ & $-0,02$ & $0,37 * *$ & $0,10^{* *}$ & $-0,45 * *$ & & $-0,17 * *$ & $0,05^{*}$ \\
\hline PER & $-0,11 * *$ & $-0,33 * *$ & $-0,18 * *$ & $-0,07 * *$ & $-0,34 * *$ & $=0,33 * *$ & $-0,34 * *$ & $-0,04$ & $-0,43 * *$ & $-0,27 * *$ & $-0,29 * *$ & $-0,17 * *$ & & $-0,17 * *$ \\
\hline$N M 2$ & $0,09 * * *$ & $0,35 * *$ & $0,13 * *$ & $0,15^{* *}$ & $0,08 * *$ & $-0,16^{* *}$ & $-0,02$ & $-0,01$ & $0,18 * *$ & $0,08 * *$ & $0,14 * *$ & 0,05 & $-0,17 * *$ & \\
\hline
\end{tabular}

Obs.: **,* significante a $1 \%$ e $5 \%$, respectivamente. Todas as variáveis contínuas foram winsorizadas a $1 \%$ e $99 \%$. A amostra consiste em 2.444 observações, das quais 1.491 são pagadoras de dividendos e 953 são não pagadoras de dividendos, no período de 2003 a 2012 . No triângulo inferior da matriz é apresentada a correlação de Pearson enquanto na parte superior é evidenciada a correlação de Spearman. $A C C D=$ gerenciamento de resultados, tendo como proxy o valor dos accruals discricionários estimados pela equação $(2) ; D I V=$ Variável dummy, 1 caso ocorra pagamento de dividendos, 0 caso contrário; $P$ DIV = Variável dummy, 1 caso ocorra o pagamento de dividendos de forma frequente durante 4 ou mais anos (t-3 a t), 0 caso contrário; $B \bar{I} G$ _ DIV = variável dummy, 1 caso o payout seja superior a $0,25,0$ caso contrário; SMALL_DIV = variável dummy, 1 caso o payout seja inferior a 0,25, 0 caso contrário; TAM= Logaritmo Natural do Ativo Total;

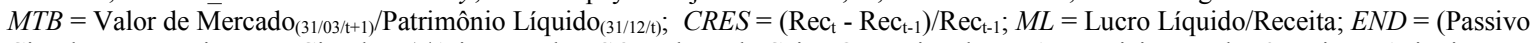
Circulante + Passivo Não Circulante)/Ativo Total; $F C O=$ Fluxo de Caixa Operacional; $P M A=$ Participação dos 3 Maiores Acionistas, calculado pela razão entre as ações ordinárias pertencentes aos maiores acionistas e o total de ações da empresa; $P E R=$ Variável $d u m m y, 1$ 
caso EBITDA $<0,0$ caso contrário e $N M 2=$ dummy, 1 quando listada no Nível 1(N1), Nível 2 (N2) ou Novo Mercado (NM) e 0 caso contrário.

Fonte: Dados da pesquisa.

Não foram detectados valores elevados (acima de 0,80) de correlação entre as variáveis explanatórias, resultando em uma boa qualidade do ajustamento dos dados contidos no modelo. Logo, pode-se indicar ausência de acentuada multicolinearidade. Entretanto, esta análise trata-se de um procedimento preliminar, tendo em vista a possibilidade de existência de multicolinearidade, mesmo em variáveis com baixas correlações (GUJARATI, 2006, p. 289-290).

Adicionalmente, foram realizados os testes de fator de inflação da variância (VIF), para detectar a presença de multicolinearidade nos modelos propostos. Os resultados da média VIF obtidos foram os seguintes: (i) equação 3 (Estatística de 1,28); (ii) equação 4 (Estatística de 1,25) e (iii) equação 5 (Estatística de 1,31). Como os valores do teste VIF são inferiores a 10 , podemos aceitar a inexistência de problemas graves relacionados à multicolinearidade (GUJARATI, 2006, p. 292).

\subsection{Análise dos Resultados das Regressões}

A Tabela 4 apresenta os resultados das regressões com o objetivo de testar a hipótese de pesquisa. As regressões estimadas foram ajustadas em clusters por setor e ano, obtendo dessa forma 19 clusters (setores) e 10 anos (período de 2003 a 2012). Foram ainda estimadas regressões (não divulgadas), com a inserção de dummies para identificar o setor de cada firma pertencente à amostra.

A primeira regressão (equação 3) com vistas a testar a hipótese de que empresas distribuidoras de dividendos possuem lucros de melhor qualidade, ou seja, com menores níveis de accruals discricionários (gerenciamento de resultado) não pôde ser confirmada. Tendo em vista o sinal positivo e significativo da variável $D I V(2,24)$, podemos inferir que, a realização de pagamento de dividendos, pelas empresas pertencentes à amostra do estudo, não reduz os níveis dos accruals discricionários, ou seja, o gerenciamento de resultados. Dessa forma, a realização de pagamento de dividendo não representa um indicativo de melhor qualidade do lucro contábil. Logo, o pagamento de dividendos, no Brasil, parece não estar associado a uma redução de gerenciamento de resultados.

Em relação ao teste da "persistência" dos dividendos, ou seja, verificar se empresas que distribuem dividendos com frequência possuem menores níveis de accruals discricionários (equação 4), a variável $P_{-} D I V(1,88)$, indicadora se a empresa realizou o pagamento durante 4 (quatro) ou mais anos consecutivos, obteve sinal positivo e significativo. Em outras palavras, mesmo as empresas da amostra que realizaram pagamento de dividendos com frequência, não necessariamente reportaram lucros de melhor qualidade.

As firmas também foram classificadas em grandes pagadoras de dividendos (BIG DIV) e pequenas pagadoras de dividendos (SMALL DIV), objetivando verificar se as empresas com maiores níveis de distribuição de dividendos por ação, medido pelo payout superior a 0,25, possuem menores níveis de accruals discricionários (equação 5).

Os achados indicam que as empresas que realizam maiores pagamentos de dividendos ( $B I G D I V)$ estão associadas a maiores níveis de gerenciamento de resultados. Assim, parece inesperado que empresas pagadoras de maiores dividendos estejam relacionadas a lucros de qualidade inferior ao das empresas pagadoras de menores dividendos. 
Tabela 4 - Resultado das regressões robustas com erros clusterizados estimados

$A C C D=\beta_{0}+\beta_{I} D I V+\beta_{2} T A M+\beta_{3} M T B+\beta_{4} C R E S+\beta_{5} M L+\beta_{6} E N D+\beta_{7} F C O+\beta_{8} P M A+\beta_{9} P E R+\beta_{10} N M 2+\varepsilon$ (3)

$A C C D=\beta_{0}+\beta_{1} P$ DIV $+\beta_{2} T A M+\beta_{3} M T B+\beta_{4} C R E S+\beta_{5} M L+\beta_{6} E N D+\beta_{7} F C O+\beta_{8} P M A+\beta_{9} P E R+\beta_{10} N M 2+\varepsilon$ (4)

$A C C D=\beta_{0}+\beta_{1} B I G \_D I V+\beta_{2} S M A L L \_D I V+\beta_{3} T A M+\beta_{4} M T B+\beta_{5} C R E S+\beta_{6} M L+\beta_{7} E N D+\beta_{8} F C O+\beta_{9} P M A+\beta_{10} P E R+\beta_{11} N M 2+\varepsilon$ (5)

\begin{tabular}{|c|c|c|c|c|c|c|c|}
\hline \multirow{2}{*}{$\begin{array}{c}\text { Variáveis } \\
\text { Explanatórias }\end{array}$} & \multirow{2}{*}{$\begin{array}{c}\text { Sinal } \\
\text { Predito }\end{array}$} & \multicolumn{2}{|c|}{ Equação (3) } & \multicolumn{2}{|c|}{ Equação (4) } & \multicolumn{2}{|c|}{ Equação (5) } \\
\hline & & Coeficiente & t-Stat & Coeficiente & t-Stat & Coeficiente & t-Stat \\
\hline DIV & - & $2,240 * * *$ & $(2,96)$ & & & & \\
\hline$P_{-} D I V$ & - & & & $1,880 * * *$ & $(2,90)$ & & \\
\hline BIG_DIV & - & & & & & $2,270 * * *$ & $(2,77)$ \\
\hline$S M A L L \_D I V$ & - & & & & & $2,170 * * *$ & $(2,99)$ \\
\hline $\boldsymbol{T A M}$ & - & $-1,160 * * *$ & $(-5,94)$ & $-1,160 * * *$ & $(-5,88)$ & $-1,160 * * *$ & $(-5,93)$ \\
\hline$M T B$ & + & $0,352 * * *$ & $(3,04)$ & $0,353 * * *$ & $(3,05)$ & $0,352 * * *$ & $(3,07)$ \\
\hline CRES & + & $3,060 * * *$ & $(3,02)$ & $3,160 * * *$ & $(3,25)$ & $3,070 * * *$ & $(3,08)$ \\
\hline$M L$ & + & $0,949 * *$ & $(2,07)$ & $0,944 * *$ & $(2,10)$ & $0,950 * *$ & $(2,07)$ \\
\hline$E N D$ & $+/-$ & $-0,498$ & $(-0,65)$ & $-0,565$ & $(-0,73)$ & $-0,498$ & $(-0,65)$ \\
\hline$F C O$ & + & $-61,700 * * *$ & $(-8,63)$ & $-61,700 * * *$ & $(-8,63)$ & $-61,700 * * *$ & $(-8,62)$ \\
\hline$P M A$ & + & $3,000 *$ & $(1,74)$ & $3,200 *$ & $(1,85)$ & $3,000 *$ & $(1,74)$ \\
\hline$P E R$ & - & $-14,600 * * *$ & $(-10,90)$ & $-15,100 * * *$ & $(-12,17)$ & $-14,600 * * *$ & $(-11,01)$ \\
\hline$N M 2$ & - & 0,320 & $(0,37)$ & 0,469 & $(0,57)$ & 0,318 & $(0,37)$ \\
\hline CONS & $+/-$ & $19,400 * * *$ & $(9,79)$ & $19,900 * * *$ & $(10,36)$ & $19,400 * * *$ & $(9,95)$ \\
\hline $\operatorname{Ad} . R^{2}$ & & \multicolumn{2}{|c|}{56,17} & \multicolumn{2}{|c|}{56,11} & \multicolumn{2}{|c|}{56,17} \\
\hline F-Stat & & \multicolumn{2}{|c|}{$109,64 * * *$} & \multicolumn{2}{|c|}{$108,91 * * *$} & \multicolumn{2}{|c|}{$99,70 * * *$} \\
\hline Observações & & \multicolumn{2}{|c|}{2.444} & \multicolumn{2}{|c|}{2.444} & \multicolumn{2}{|c|}{2.444} \\
\hline Setores & & \multicolumn{2}{|c|}{19} & \multicolumn{2}{|c|}{19} & \multicolumn{2}{|c|}{19} \\
\hline Ano & & \multicolumn{2}{|l|}{10} & \multicolumn{2}{|l|}{10} & \multicolumn{2}{|c|}{10} \\
\hline
\end{tabular}

Obs.: ***,**,* significante a $1 \%, 5 \%$ e $10 \%$, respectivamente. Regressão robusta com erros clusterizados no setor e ano corrigidos para heterocedasticidade. Para melhor visualização dos dados os coeficientes foram multiplicados por 100. Todas as variáveis contínuas foram winsorizadas a $1 \%$ e $99 \%$. ACCD = gerenciamento de resultados, tendo como proxy o valor dos accruals discricionários estimados pela equação $(2) ; \quad D I V=$ Variável dummy, 1 caso ocorra pagamento de dividendos, 0 caso contrário; $P$ DIV = Variável dummy, 1 caso ocorra o pagamento de dividendos de forma frequente durante 4 ou mais anos (t-3 a t), 0 caso contrário; $B I G \_D I V$ = variável dummy, 1 caso o payout seja superior a $0,25,0$ caso contrário; $S M A L L \_D I V=$ variável dummy, 1 caso o payout seja inferior a 0,25, 0 caso contrário; TAM= Logaritmo Natural do Ativo Total; $M T B=$

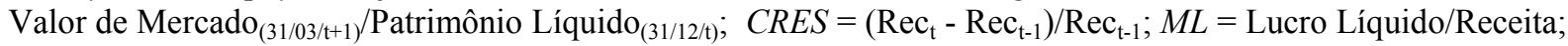
$E N D=($ Passivo Circulante + Passivo Não Circulante $) /$ Ativo Total; $F C O=$ Fluxo de Caixa Operacional; $P M A=$ Participação dos 3 Maiores Acionistas; $P E R=$ Variável dummy, 1 caso EBITDA $<0,0$ caso contrário e NM2= dummy, 1 quando listada no Nível 1(N1), Nível 2 (N2) ou Novo Mercado (NM) e 0 caso contrário.

Fonte: Dados da pesquisa.

Dentre as variáveis de controle ressalta-se o fato da variável de concentração acionária (PMA) estar relacionada com maiores níveis de gerenciamento de resultados. Quanto maior a concentração acionária maior o incentivo de o gestor manipular os números contábeis, reduzindo a qualidade do lucro.

A variável indicadora de adesão a melhores segmentos de governança corporativa (NM2) não foi estatisticamente significativa. Nesse cenário, e em conformidade com Leuz, 
Nanda e Wysocki (2003), os resultados das regressões demonstram que o fraco ambiente institucional corrobora com as práticas de gerenciamento de resultados das firmas.

Dessa forma, no mercado de ações brasileiro, a política de dividendos não reflete uma melhor qualidade do lucro contábil. Embora o pagamento de dividendos requeira necessidade de caixa, para suportar o desembolso, não foram encontradas evidências de que o pagamento contribui para a redução do nível de gerenciamento de resultados. Assim, os resultados deste trabalho divergiram da pesquisa de Tong e Miao (2011), onde encontraram uma relação positiva entre dividendos e lucros de melhor qualidade.

Aspectos relacionados ao incentivo tributário ou até mesmo a preferência do investidor brasileiro, pelo recebimento de dividendos, em razão de uma possível proteção, caso o preço da ação caia (DECOURT; PROCIANOY, 2012), podem fornecer explicação a respeito dos achados. Outro aspecto que pode fornecer explicação complementar está relacionado ao efeito que a vinculação das práticas contábeis às normas tributárias exerce sobre o conteúdo informacional do lucro no Brasil (REZENDE; NAKAO, 2012).

\subsection{Análise Adicional}

Adicionalmente, foram estimadas regressões separando os sinais dos accruals discricionários, conforme Tabela 5, gerando duas bases de dados. A primeira base contem apenas os accruals discricionários negativos com um total de 1.491 observações (Painel A) e a segunda com os accruals discricionários positivos com 953 observações (Painel B). Este procedimento é semelhante ao adotado por (CARAMANIS; LENNOX, 2008).

Tendo em vista que esta estimação é truncada (os accruals discricionários positivos estão dispostos à direita enquanto os negativos estão dispostos à esquerda), optou-se por estimar a regressão clusterizada na firma e no ano, com a inserção de variáveis dummies por setor, para melhor controle.

Em relação aos accruals discricionários negativos (Painel A), os coeficientes das variáveis de interesse, com exceção da variável SMALL DIV que não apresentou significância estatística, permitem chegar à conclusão de que empresas pagadoras de dividendos reduzem o nível do gerenciamento dos accruals discricionários negativos. Neste cenário as empresas que realizam o pagamento dos dividendos minimizam o reporte de perdas, tendo em vista que a variável $B I G_{-} D I V(-1,540)$ apresentou significância estatística a $1 \%$ e sinal negativo, indicando que as empresas com maiores níveis de payout evitam reduzir o nível do lucro reportado por meio de gerenciamento de resultados.

No que tange aos accruals discricionários positivos (Painel B) o coeficiente de interesse foi significativo apenas a $10 \%$ e com sinais positivos apenas para as variáveis $D I V$ $(1,82)$ e $S M A L L D I V(2,19)$. Com isso observa-se que, entre as empresas pagadoras de dividendos, aquelas com menores níveis de payout, elevam os accruals discricionários positivos, com a finalidade de reportar lucros e realizar o pagamento dos dividendos. Entretanto ressalta-se que a fraca significância estatística pode relacionar-se ao recorte metodológico da amostra e indica a necessidade de testes adicionais para reforçar esta evidência. 
Dividendos e accruals discricionários: um estudo sobre a relação entre a política de distribuição de dividendos...

\begin{tabular}{|c|c|c|c|c|c|c|}
\hline \multicolumn{7}{|c|}{$\begin{array}{c}A C C D=\beta_{0}+\beta_{1} D I V+\beta_{2} T A M+\beta_{3} M T B+\beta_{4} C R E S+\beta_{5} M L+\beta_{6} E N D+\beta_{7} F C O+\beta_{8} P M A+\beta_{9} P E R+\beta_{10} N M 2+\varepsilon \text { (3) } \\
A C C D=\beta_{0}+\beta_{1} P \_D I V+\beta_{2} T A M+\beta_{3} M T B+\beta_{4} C R E S+\beta_{5} M L+\beta_{6} E N D+\beta_{7} F C O+\beta_{8} P M A+\beta_{9} P E R+\beta_{10} N M 2+\varepsilon \text { (4) } \\
A C C D=\beta_{0}+\beta_{1} B I G \_D I V+\beta_{2} S M A L L \_D I V+\beta_{3} T A M+\beta_{4} M T B+\beta_{5} C R E S+\beta_{6} M L+\beta_{7} E N D+\beta_{8} F C O+\beta_{9} P M A+\beta_{10} P E R+\beta_{11} N M 2+\varepsilon \text { (5) }\end{array}$} \\
\hline \multicolumn{7}{|c|}{ Painel A - Accruals Discricionários Negativos - $\mid$ ACCD $\mid$} \\
\hline \multirow{2}{*}{$\begin{array}{c}\text { Variáveis } \\
\text { Explanatórias }\end{array}$} & \multicolumn{2}{|c|}{ Equação (3) } & \multicolumn{2}{|c|}{ Equação (4) } & \multicolumn{2}{|c|}{ Equação (4) } \\
\hline & Coeficiente & t-Stat & Coeficiente & t-Stat & Coeficiente & t-Stat \\
\hline DIV & $-1,250 * *$ & $(-2,25)$ & & & & \\
\hline$P_{-} D I V$ & & & $-0,964 * *$ & $(-2,00)$ & & \\
\hline$B I G \_D I V$ & & & & & $-1,540 * * *$ & $(-2,65)$ \\
\hline SMALL_DIV & & & & & $-0,495$ & $(-0,81)$ \\
\hline Ad. $\mathbf{R}^{2}$ & 47,76 & & 47,6 & & 47,8 & \\
\hline F-Stat & $25,54 * * *$ & & $24,31^{\prime}$ & & $24,86^{*}$ & \\
\hline Observações & 1.491 & & 1.49 & & 1.49 & \\
\hline Clusters & 373 & & 373 & & 373 & \\
\hline Anos & 10 & & 10 & & 10 & \\
\hline
\end{tabular}

\begin{tabular}{|c|c|c|c|c|c|c|c|}
\hline \multirow[t]{2}{*}{ Anos } & \multicolumn{2}{|c|}{10} & \multicolumn{2}{|c|}{10} & \multicolumn{3}{|c|}{10} \\
\hline & \multicolumn{7}{|c|}{ Painel B - Accruals Discricionários Positivos - ACCD } \\
\hline \multirow{2}{*}{$\begin{array}{c}\text { Variáveis } \\
\text { Explanatórias }\end{array}$} & \multicolumn{2}{|c|}{ Equação (3) } & \multicolumn{2}{|c|}{ Equação (4) } & \multicolumn{3}{|c|}{ Equação (5) } \\
\hline & Coeficiente & t-Stat & Coeficiente & t-Stat & Coeficie & ente & t-Stat \\
\hline$D I V$ & $1,820 *$ & $(1,68)$ & & & & & \\
\hline P_DIV & & & 1,060 & $(1,31)$ & & & \\
\hline BIG_DIV & & & & & 1,600 & & $(1,42)$ \\
\hline$S M A L L \_D I V$ & & & & & 2,190 & $*$ & $(1,92)$ \\
\hline Ad. $R^{2}$ & 63 , & & 63 , & & & 63 , & \\
\hline F-Stat & 27,72 & & 28,1 & & & 6,84 & \\
\hline Observações & 95 & & 95 & & & 95 & \\
\hline Clusters & 31 & & 31 & & & 31 & \\
\hline Anos & 10 & & 1 & & & 10 & \\
\hline
\end{tabular}

Obs.: ***,**** significante a 1\%, 5\% e 10\%, respectivamente. Regressão robusta com erros clusterizados na firma e ano corrigidos para heterocedasticidade, com a inserção de variáveis dummies por setor. Para melhor visualização dos dados os coeficientes foram multiplicados por 100. Todas as variáveis contínuas foram winsorizadas a $1 \%$ e $99 \%$. $|A C C D|=$ gerenciamento de resultados, tendo como proxy o valor absoluto dos accruals discricionários estimados pela equação (2); DIV = Variável dummy, 1 caso ocorra pagamento de dividendos, 0 caso contrário; $P_{-} D I V=$ Variável dummy, 1 caso ocorra o pagamento de dividendos de forma frequente durante 4 ou mais anos (t-3 a t), 0 caso contrário; $B I G \_D I V=$ variável dummy, 1 caso o payout seja superior a 0,25, 0 caso contrário; SMALL_DIV = variável dummy, 1 caso o payout seja inferior a $0,25,0$ caso contrário. As demais variáveis foram omitidas por conveniência.

Fonte: Dados da pesquisa.

O interesse em atender a preferência do investidor pelo recebimento do dividendo parece se realçar e influenciar na decisão de reportar o lucro da firma. Em ambos os casos, tanto nas empresas com accruals anormais positivos, quanto nas empresas com accruals anormais negativos, as empresas pagadoras de dividendos utilizam os accruals discricionários como forma de elevar (ou não reduzir) o lucro reportado e então realizar o pagamento de dividendos. 


\subsection{Análise de Sensibilidade}

Para testar a sensibilidade do método adotado na obtenção dos accruals discricionários, foram elaborados dois modelos. Os accruals discricionários foram estimados, valendo-se do modelo modificado de Jones (1991), sem a constante e com a inclusão da constante. Esta estimação é diferente da adotada no presente trabalho, pois se seguiu a recomendação de Kothari, Leone e Wasley (2005) ao ajustar o modelo modificado de Jones (1991) com a inclusão da variável ROA (retorno sobre o ativo) e a constante no modelo.

Com exceção de alguns níveis de significância estatística dos coeficientes, os resultados apresentados no presente trabalho, assemelham-se aos da estimação dos accruals discricionários obtidos por meio do modelo modificado de Jones (1991), tanto com a presença da constante quanto sem a presença constante.

Valendo-se de um método alternativo de análise de sensibilidade e, considerando o tamanho da amostra, estimaram-se regressões robustas por MQO, com erros padrões consistentes para heterocedasticidade de White, adotando-se dummies para identificar os setores das firmas pertencentes à amostra (GUJARATI, 2006; WOOLDRIDGE, 2010). Os resultados encontrados também foram consistentes com os apresentados na tabela 4 , tanto para os accruals estimados com a constante quanto para os accruals estimados sem a constante (ajustados ou não pelo ROA).

\section{Conclusões}

O presente artigo teve como objetivo identificar a existência de relação entre a política de dividendos e o gerenciamento do lucro contábil, das companhias listadas na BM\&FBovespa, no período compreendido entre 2003 e 2012. A qualidade do lucro contábil foi medida por meio dos accruals discricionários (gerenciamento de resultados) estimados pelo modelo modificado de Jones (1991), com o ajuste de desempenho da firma sugerido por Kothari, Leone e Wasley (2005).

A premissa adotada na elaboração do presente estudo é de que o pagamento de dividendo é um indicador de qualidade do lucro contábil, ou seja, um menor nível de gerenciamento de resultados. Ora, caso a firma declare um lucro, este deverá possuir fluxos de caixa o suficiente para suportar a saída financeira em relação aos pagamentos de dividendos. Nesse contexto, o pagamento de dividendos exerce um papel indicativo de lucros com baixos níveis de accruals discricionários.

Entretanto, os achados do presente estudo não corroboraram com a premissa de que os dividendos são indicadores de menores níveis de accruals discricionários. Os resultados das regressões estimadas indicam que, as firmas pagadoras de dividendos não possuem menores níveis de gerenciamento de resultados, ou seja, não há relação entre pagamentos de dividendos e qualidade do lucro contábil, no mercado brasileiro. Os resultados são robustos inclusive na condição de persistência no pagamento dos dividendos.

Analisando o sinal dos accruals discricionários, percebe-se que tanto em empresas com accruals anormais positivos, quanto nas empresas com accruals anormais negativos, as empresas pagadoras de dividendos utilizam os accruals discricionários como forma de elevar o lucro reportado (ou evitar que ele seja tenha redução significativa) e então realizar o pagamento de dividendos. 
Tais achados podem ser atribuídos ao ambiente institucional do Brasil, no qual devido à interferência da legislação (obrigatoriedade de distribuição/não tributação dos dividendos), alteram os incentivos dos gestores, no que tange ao reporte dos lucros. O comportamento do investidor brasileiro, relacionado à preferência, no recebimento de dividendos, em razão de uma possível proteção, caso o preço da ação caia, pode fornecer explicações complementares a respeito dos achados (DECOURT; PROCIANOY, 2012, p. 463).

Com relação às limitações deste trabalho ressalta-se que o período analisado contempla o período de transição ao padrão IFRS no Brasil, o que pode prejudicar a estimação dos accruals discricionários. Considera-se a falta de divulgação da demonstração do fluxo de caixa nos períodos anteriores a transição ao padrão internacional, uma segunda limitação do trabalho, pois inviabilizou a estimação dos accruals pelo fluxo de caixa.

\section{Referências}

ABREU, A. F. DE. As Proposições de Modigliani e Miller e a tributação brasileira. XXVI EnANPAD. Anais... In: XXVI ENCONTRO DA ANPAD - ENANPAD. Salvador/BA:

ANPAD, 2002Disponível em: < http://www.anpad.org.br/diversos/trabalhos/EnANPAD/en anpad_2002/FIN/2002_FIN1251.pdf >. Acesso em: 30 nov. 2013

BARTOV, E.; GUL, F. A.; TSUI, J. S. L. Discretionary-accruals models and audit qualifications. Journal of Accounting and Economics, v. 30, n. 3, p. 421-452, dez. 2000.

BECKER, C. L. et al. The Effect of Audit Quality on Earnings Management. Contemporary Accounting Research, v. 15, n. 1, p. 1-24, mar. 1998.

BERGSTRESSER, D.; DESAI, M.; RAUH, J. Earnings Manipulation, Pension Assumptions, and Managerial Investment Decisions. The Quarterly Journal of Economics, v. 121, n. 1, p. 157-195, 1 fev. 2006.

BORTOLON, P. M. Por que as empresas brasileiras adotam estruturas piramidais de controle. BASE - Revista de Administração e Contabilidade da Unisinos, v. 10, n. 1, p. 2-18, 2013.

BOUlTON, T. J.; BRAGA-ALVES, M. V.; SHASTRI, K. Payout policy in Brazil: Dividends versus interest on equity. Journal of Corporate Finance, v. 18, n. 4, p. 968-979, set. 2012.

BRASIL. Lei n ${ }^{\circ}$ 6.404, de 15 de dezembro de 1976. Dispõe sobre as Sociedades por Ações. 1976.

BRASIL. Lei $\mathrm{n}^{\circ}$ 9.249, de 26 de dezembro de 1995. Altera a legislação do imposto de renda das pessoas jurídicas, bem como da contribuição social sobre o lucro líquido, e dá outras providências. 1995.

BREALEY, R. A.; MYERS, S. C.; ALLEN, F. Princípios de Finanças Corporativas. Tradução Maria do Carmo Figueira; Nuno de Carvalho. 8. ed. Porto Alegre: AMGH, 2008. 
BRENNAN, M. J. Taxes, Market Valuation and Corporate Financial Policy. National Tax Journal, v. 23, n. 4, p. 417-427, dez. 1970.

CARAMANIS, C.; LENNOX, C. Audit effort and earnings management. Journal of Accounting and Economics, v. 45, n. 1, p. 116-138, mar. 2008.

CHEN, S.; SHEVLIN, T.; TONG, Y. H. Does the Pricing of Financial Reporting Quality Change Around Dividend Changes? Journal of Accounting Research, v. 45, n. 1, p. 1-40, mar. 2007.

DANIEL, N. D.; DENIS, D. J.; NAVEEN, L. Do firms manage earnings to meet dividend thresholds? Journal of Accounting and Economics, v. 45, n. 1, p. 2-26, mar. 2008.

DECHOW, P. M.; GE, W.; SCHRAND, C. Understanding earnings quality: A review of the proxies, their determinants and their consequences. Journal of Accounting and Economics, v. 50, n. 2-3, p. 344-401, dez. 2010.

DECHOW, P. M.; SLOAN, R. G.; SWEENEY, A. P. Detecting Earnings Management. The Accounting Review, v. 70, n. 2, p. 193-225, 1 abr. 1995.

DECOURT, R. F.; PROCIANOY, J. L. O Processo Decisório sobre a Distribuição de Lucros das Empresas Listadas na BM\&FBOVESPA: Survey com CFOs. Revista Brasileira de Finanças, v. 10, n. 4, p. 461-498, 24 dez. 2012.

DEGEORGE, F.; PATEL, J.; ZECKHAUSER, R. Earnings Management to Exceed Thresholds. The Journal of Business, v. 72, n. 1, p. 1-33, jan. 1999.

DUCHARME, L. L.; MALATESTA, P. H.; SEFCIK, S. E. Earnings management, stock issues, and shareholder lawsuits. Journal of Financial Economics, v. 71, n. 1, p. 27-49, jan. 2004.

EASTERBROOK, F. H. Two Agency-Cost Explanations of Dividends. The American Economic Review, v. 74, n. 4, p. 650-659, 1 set. 1984.

ERFURTH, A. E.; BEZERRA, F. A. Gerenciamento de resultados nos diferentes níveis de governança corporativa. BASE - Revista de Administração e Contabilidade da Unisinos, v. 10, n. 1, p. 32-42, 20 set. 2012.

FAMA, E. F.; FRENCH, K. R. Disappearing dividends: changing firm characteristics or lower propensity to pay? Journal of Financial Economics, v. 60, n. 1, p. 3-43, abr. 2001.

FIELDS, T. D.; LYS, T. Z.; VINCENT, L. Empirical research on accounting choice. Journal of Accounting and Economics, v. 31, n. 1-3, p. 255-307, set. 2001.

FORMIGONI, H.; ANTUNES, M. T. P.; PAULO, E. Diferença entre o Lucro Contábil e Lucro Tributável: Uma Análise sobre o Gerenciamento de Resultados Contábeis e 
Gerenciamento Tributário nas Companhias Abertas Brasileiras. BBR - Brazilian Business

Review, v. 6, n. 1, p. 44-61, jan. 2009.

GRULLON, G. et al. Dividend Changes Do Not Signal Changes in Future Profitability. The Journal of Business, v. 78, n. 5, p. 1659-1682, set. 2005.

GRULLON, G.; MICHAELY, R.; SWAMINATHAN, B. Are Dividend Changes a Sign of Firm Maturity? The Journal of Business, v. 75, n. 3, p. 387-424, 1 jul. 2002.

GUJARATI, D. N. Econometria Básica. Tradução Maria José Cyhlar Monteiro. 4. ed. Rio de Janeiro: Elsevier, 2006.

HANLON, M.; MYERS, J. N.; SHEVLIN, T. J. Are Dividends Informative About Future Earnings?: Working Paper. Rochester, NY: [s.n.]. Disponível em: $<$ http://papers.ssrn.com/ab stract $=964279>$. Acesso em: 16 nov. 2013.

HEALY, P. M. The effect of bonus schemes on accounting decisions. Journal of Accounting and Economics, v. 7, n. 1-3, p. 85-107, abr. 1985.

HEALY, P. M.; PALEPU, K. G. Earnings information conveyed by dividend initiations and omissions. Journal of Financial Economics, v. 21, n. 2, p. 149-175, set. 1988.

HEALY, P. M.; WAHLEN, J. M. A Review of the Earnings Management Literature and Its Implications for Standard Setting. Accounting Horizons, v. 13, n. 4, p. 365-383, dez. 1999.

HENINGER, W. G. The Association Between Auditor Litigation and Abnormal Accruals. The Accounting Review, v. 76, n. 1, p. 111-126, 2001.

HOLANDA, A. P.; COELHO, A. C. D. Dividendos e efeito clientela: evidências no mercado brasileiro. Revista de Administração de Empresas, v. 52, n. 4, p. 448-463, ago. 2012.

IQUIAPAZA, R. A.; LAMOUNIER, W. M.; AMARAL, H. F. Assimetria de informações e pagamento de dividendos na Bovespa. Advances in Scientific and Applied Accounting, v. 1, n. 1,8 jul. 2008.

JONES, J. J. Earnings Management During Import Relief Investigations. Journal of Accounting Research, v. 29, n. 2, p. 193, 1991.

JUNIOR, W. O. F. et al. Evidências Empíricas dos Fatores Determinantes das Políticas de Dividendos das Firmas Listadas na Bovespa. FACEF Pesquisa - Desenvolvimento e Gestão, v. 13, n. 2, 2010.

KOTHARI, S. P.; LEONE, A. J.; WASLEY, C. E. Performance matched discretionary accrual measures. Journal of Accounting and Economics, v. 39, n. 1, p. 163-197, fev. 2005. 
LEUZ, C.; NANDA, D.; WYSOCKI, P. D. Earnings management and investor protection: an international comparison. Journal of Financial Economics, v. 69, n. 3, p. 505-527, set. 2003.

LEVINE, D. M. et al. Estatística - Teoria e Aplicações: usando Microsoft ${ }^{\circledR}$ Excel em português. Tradução Teresa Cristina Padilha De Souza. 6. ed. Rio de Janeiro: LTC, 2012.

LITZENBERGER, R. H.; RAMASWAMY, K. The effect of personal taxes and dividends on capital asset prices. Journal of Financial Economics, v. 7, n. 2, p. 163-195, jun. 1979.

LO, K. Earnings management and earnings quality. Journal of Accounting and Economics, v. 45, n. 2-3, p. 350-357, ago. 2008.

LOSS, L.; SARLO NETO, A. Política de dividendos, na prática, é importante? Revista Contabilidade \& Finanças, v. 14, n. SPE, p. 39-53, out. 2003.

LUSTOSA, P. R. B. et al. Estimativas contábeis e qualidade do lucro: análise setorial no Brasil. Revista de Educação e Pesquisa em Contabilidade (REPeC), v. 4, n. 2, p. 43-61, 17 ago. 2010.

MARTINEZ, A. L. Detectando Earnings management no Brasil: estimando os accruals discricionários. Revista Contabilidade \& Finanças, v. 19, n. 46, p. 7-17, abr. 2008.

MARTINS, A. I.; FAMÁ, R. O que revelam os estudos realizados no Brasil sobre política de dividendos? Revista de Administração de Empresas, v. 52, n. 1, p. 24-39, fev. 2012.

MCNICHOLS, M. F. Research design issues in earnings management studies. Journal of Accounting and Public Policy, v. 19, n. 4-5, p. 313-345, dez. 2000.

MILLER, M. H.; MODIGLIANI, F. Dividend Policy, Growth, and the Valuation of Shares. The Journal of Business, v. 34, n. 4, p. 411-433, 1 out. 1961. MOTA, D. C.; EID JÚNIOR, W. Distribuindo os Lucros. GV-executivo, v. 6, n. 3, p. 31-35, jun. 2007.

MYERS, J. N.; MYERS, L. A.; OMER, T. C. Exploring the Term of the Auditor-Client Relationship and the Quality of Earnings: A Case for Mandatory Auditor Rotation? The Accounting Review, v. 78, n. 3, p. 779-799, 1 jul. 2003.

PEROBELli, F. F. C.; SANTOS, A. B. DOS. Vale a Pena Investir em Ações High Yield? Novas Evidências sobre o Efeito do Pagamento de Dividendos e Juros sobre Capital Próprio sobre os Preços das Ações Brasileiras. XXX EnANPAD. Anais... In: XXX ENCONTRO DA ANPAD - ENANPAD. Salvador/BA: ANPAD, 2006Disponível em: $<$ http://www.anpad.org.br/diversos/trabalhos/EnANPAD/enanpad_2006/FIC/2006_FICDTC. pdf $>$. Acesso em: 30 nov. 2013 
PEROBELLI, F. F. C.; ZANINI, A.; SANTOS, A. B. DOS. Pagamento de proventos versus preços de ações maduras e em expansão segundo Kohonen Maps. Revista de Administração de Empresas, v. 49, n. 2, p. 132-146, jun. 2009.

PETERSEN, M. A. Estimating Standard Errors in Finance Panel Data Sets: Comparing Approaches. Review of Financial Studies, v. 22, n. 1, p. 435-480, 2 abr. 2009.

PROCIANOY, J. L.; VERDI, R. DOS S. O Efeito Clientela no Mercado Brasileiro: Será que os Investidores São Irracionais? Revista Brasileira de Finanças, v. 1, n. 2, p. pp. 217-242, 12 jan. 2003.

PROCIANOY, J. L.; VERDI, R. S. Dividend clientele, new insights, and new questions: the Brazilian case. RAE eletrônica, v. 8, n. 1, p. 0-0, jun. 2009.

REZENDE, G. P.; NAKAO, S. H. Gerenciamento de Resultados e a Relação com o Lucro Tributável das Empresas Brasileiras de Capital Aberto. Revista Universo Contábil, v. 8, n. 1, p. 06-21, 30 jan. 2012.

SANTOS, A. G. Q. D. et al. A Influência da Tributação sobre Dividendos e Juros sobre o Capital Próprio no Comportamento dos Preços das Ações: uma Análise Empírica na Bovespa. XXVIII EnANPAD. Anais... In: XXVIII ENCONTRO DA ANPAD - ENANPAD. Curitiba/PR: ANPAD, 2004. Disponível em: <http://www.anpad.org.br/diversos/trabalhos/En ANPAD/enanpad_2004/FIN/2004_FIN763.pdf>. Acesso em: 30 nov. 2013

SHIVAKUMAR, L. Do firms mislead investors by overstating earnings before seasoned equity offerings? Journal of Accounting and Economics, v. 29, n. 3, p. 339-371, jun. 2000.

SKINNER, D. J.; SOLTES, E. What do dividends tell us about earnings quality? Review of Accounting Studies, v. 16, n. 1, p. 1-28, 25 set. 2009.

SOUZA, J. A. S. DE et al. Determinantes e Consequências do Fechamento de Capital nas Práticas de Gerenciamento de Resultados. Revista Evidenciação Contábil \& Finanças, v. 1, n. 1, p. 38-57, 23 jul. 2013.

TONG, Y. H.; MIAO, B. Are Dividends Associated with the Quality of Earnings?

Accounting Horizons, v. 25, n. 1, p. 183-205, mar. 2011.

WARFIELD, T. D.; WILD, J. J.; WILD, K. L. Managerial ownership, accounting choices, and informativeness of earnings. Journal of Accounting and Economics, v. 20, n. 1, p. 6191, jul. 1995.

WATTS, R. L.; ZIMMERMAN, J. L. Positive Accounting Theory. Englewood Cliffs: Prentice Hall, 1986.

WOOLDRIDGE, J. M. Introdução à econometria: uma abordagem moderna. São Paulo: Cengage Learning, 2010. 
